\title{
Testicular Dysfunction in Male Rats Reversed by Ethanolic Extract of Pitaya Fruit
}

\author{
Mohammad Kanedi ${ }^{1, ~ *, ~ S u t y a r s o ~}{ }^{1}$, Siti Nurjanah ${ }^{2}$, Lilik Koernia Wahidah ${ }^{2}$ \\ ${ }^{1}$ Department of Biology, Faculty of Mathematics and Sciences, University of Lampung, Bandar Lampung, Indonesia \\ ${ }^{2}$ Department of Pharmacy, Faculty of Mathematics and Sciences, Tulang Bawang University, Bandar Lampung, Indonesia \\ Email address: \\ wegayendi@yahoo.com (M. Kanedi) \\ ${ }^{*}$ Corresponding author
}

To cite this article:

Mohammad Kanedi, Sutyarso, Siti Nurjanah, Lilik Koernia Wahidah. Testicular Dysfunction in Male Rats Reversed by Ethanolic Extract of Pitaya Fruit. Journal of Diseases and Medicinal Plants. Vol. 2, No. 4, 2016, pp. 51-55. doi: 10.11648/j.jdmp.20160204.12

Received: July 15, 2016; Accepted: July 18, 2016; Published: August 26, 2016

\begin{abstract}
Sexual disorders have a great impact on men's life, so that is why efforts in searching materials and techniques for the effective treatment of safe and cheap still continued. However, many of the natural material that is claimed efficacious drugs for the high content of bioactive, particularly for sexual disorders, has not been scientifically tested. This study was designed and conducted to ascertain whether the dragon fruit (Hylocereus sp) which is claimed to be efficacious as an antioxidant as well as anti-aging, can be used as a remedy for sexual function disorders and fertility in male rats. Male Sprague-Dawley rats (Rattus novergicus) aged $10-12$ weeks, grouped in to four consisted of six rats each, treated once daily for

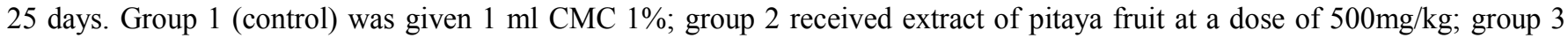
treated with cyproterone acetate (CPA) at a dose of $25 \mathrm{mg} / \mathrm{kg}$; whereas group 4 adminstered with $25 \mathrm{mg} / \mathrm{kg}$ CPA and $500 \mathrm{mg} / \mathrm{kg}$ of pitaya fruit extract. CPA treatment effectively reduces serum testosterone while pitaya fruit extract effectively enhances the androgen concentration; increases spermatozoa counts, sperm viability, sperm motility, and spermatid counts. However, pitaya fruit fail to restore the decrease of primary spermatocyte due to CPA induction. So, the conclusion white pitaya fruit extract effectively increase the synthesis of testosterone and play a role spermiogenesis, thus the pitaya fruit herbs can be used as an enhancer of sexual activity and fertility in male.
\end{abstract}

Keywords: Pitaya Fruit, Dragon Fruit, Hylocereus Sp, Antioxidant, Testicular Function, Steroidogenesis

\section{Introduction}

The testes serve two functions that are highly organized and complex called spermatogenesis and steroidogenesis. Spermatogenesis includes all the processes involved in the production of gametes whereas steroidogenesis is the entire enzymatic reactions leading to the production of male sexual hormones called androgens $[1,2]$. When either one of or both functions are impaired, for one or more reasons, then there was what is called testicular dysfunction. There are many environmental factors, either external or internal, which has been suggested to cause testicular dysfunction, such as exposure to toxic substances, noise, electronic radiation, smoke, or lifestyle [3]. Whatever the cause, testicular dysfunction may result in a decline in fertility and androgen deficiency. Both types of the disorder, especially androgen (testosterone) deficiency, greatly affect the quality of life of men, because of a decline in mood and libido, poor of concentration, difficulty in keeping erection, low energy, poor muscles strenght, and many more [4].

Due to the high influence of sexual disorders in men's life, efforts in searching materials and techniques for the treatment of sexual dysfunction which is safe andcheap still continues. So far, the drug substance which is believed with minimum side effects and is relatively inexpensive is the active ingredient isolated from plants [5]. While the research approach that remains popular to this day is to use animal models, primarily rats [6].

One type of plant which is expected to address many type of illness, due to rich in bioactive compounds, is the dragon 
fruit or pitaya (Hylocereus sp). This plant is claimed to be efficacious as anti-aging, cancer prevention, cardiovascular health, diabetes, digestion disorders, and immunity booster [7]. The red type of pitaya (Hylocereus polyrhizus) for instance, as reported by [8] is a good source of antioxidants with healthy benefits for human diet.

Such claims mainly based on the research reports which suggested that the extract of dragon fruit has various bioactives namely $\beta$-amyrin, $\alpha$-amyrin, octacosane, $\gamma$ sitosterol, octadecane, 1-tetracosanol, stigmast-4-en-3-one, campesterol, heptacosane, nonacosane, and trichloroacetic acid, hexadecyl ester [9]. Some of the bioactive compounds found in pitaya extract having strong antioxidant activity include 9, 12-octadecadienoic acid (Z, Z)-phenylmethyl ester, heptacosane and n-hexadecanoic acid [10]. The content of dragon fruit which is apparently have positive effects on sexual function in male mammals is $\beta$-sitosterol and $\alpha-\beta$ amyrin acetate [11].

The immediate effect of dragon fruit extract on testicular function parameters has reported by [12]. The findings showed pitaya fruit extract at a dose of $500 \mathrm{mg} / \mathrm{kg}$ effectively increased sperm count whereas extract of $1000 \mathrm{mg} / \mathrm{kg}$ increased sperm production and its viability. However, due to lack of studies, the effects of dragon fruit, both its peel and pulp, on the androgenic status of the animals is still unknown

The current study carried out as an effort to seek and enrich the knowledge of how to overcome sexual dysfunction and to make sure that the dragon fruit is really effective in maintaining sexual function. Given the antioxidant properties among the species of dragon fruit is highest in the white type, due to its free radical scavenging activity and ferrous ion chelating activity [13], white pitaya fruit (Hylocereus undatus) was used. Male albino rats (Rattus rattus) used as the model animals and cyproterone acetate (CPA) is used for inducing testicular dysfunction in the experimental animals. CPA chosen because in addition to effective in suppressing sperm production, the compound also causing androgen depletion that may lead the decrease in libido and sexual potency [14].

\section{Materials and Methods}

\subsection{Pitaya Fruits and Extraction}

The white pitaya fruits (Hylocereus undatus) used for the study purchased from a fruit shop in Bandar Lampung, Indonesia. To get the pulp of pitaya fruit, the fruit was peeled manually using a stainless steel knife. The fruit pulp of 2-3 g in mass was blended for 1-2 minutes until the pulp changed to pasta form. The homogeneous sample was then freezedried to lower the water content so that the process of extraction is more efficient. The homogeneous freeze samples put into a graduated cylinder and then a $250 \mathrm{ml}$ ethanol $70 \%$ was added. After being shaked for 48 hours, the mixture filtered using No. 4 What man filter paper. Filtrate evaporated using rotary-evaporator at $40^{\circ} \mathrm{C}$ for 4 hours. The ethanolic extract was suspended in 1\% CMC (carboxymethyl cellulose) and ready for use.

\subsection{Cyproterone Acetate}

Cyproterone acetate tablets with the product brand Diane35 were bought from a drugstore, Apotek Rosa, Bandar Lampung, Indonesia. Each tablet contained CPA of $2 \mathrm{mg}$ and ethinyl-estradiol of $0.035 \mathrm{mg}$. The tablets were grinded and the powder was suspended in 1\% CMC (carboxymethyl cellulose). The suspension then given to the animals via oral of $1 \mathrm{ml}$ daily for 7 days.

\subsection{Experimental Animals and Treatment}

Male Sprague-Dawley rats (Rattus novergicus) aged $10-$ 12 weeks were used for the study. The animals and the food pellets were obtained from PT. Indoanilab Bogor, West Java, Indonesia. Rats were housed in a room at the temperature of $25^{\circ} \mathrm{C}$ and 12:12-hour light-dark cycle with free access to water and pellets ad libitum. All animal care and treatment procedures were approved by the Ethics Committee, Faculty of Medicine, University of Lampung, Indonesia. By using a completely randomized design, the animals grouped in to four consisted of six rats each. Group 1 (control) was given 1 $\mathrm{ml} \mathrm{CMC} 1 \%$; group 2 received pulp extract of pitaya fruit at a dose of $500 \mathrm{mg} / \mathrm{kg}$; group 3 treated with CPA at a dose of $25 \mathrm{mg} / \mathrm{kg}$; whereas group 4 adminstered with $25 \mathrm{mg} / \mathrm{kg}$ CPA and $500 \mathrm{mg} / \mathrm{kg}$ of pitaya fruit extract. All treatments was undertaken once daily for 25 days.

\subsection{Blood and Testes Sampling}

For taking blood samples and the testes, the rats were sacrificed after being deeply anesthetized using ether, after the animals overnight fasted. The blood collected by cardiac puncture technique using open approach. By utilizing 20-25 gauge needle and 10-20 $\mathrm{ml}$ syringe the blood was drawn via vena cava of heart by slight negative pressure on the syringe. Blood samples, of about $3 \mathrm{ml}$, put into sterile empty cetrifuge tube without any anticoagulant and allowedto clot at room tempereture. The clot was removed by centrifugation at 2500 rpm for 15 minutes. The supernatant, designated serum, removed using a Pasteur pipette and stored at $-20^{\circ} \mathrm{C}$ before assayed.

Testis and epididymis is taken by dissecting the peritoneal cavity at the posterior part of the abdomen. Any excess fat or connective tissue removed from the sampled organs, and then both testis and epididymis weighed using analytical-density digital balance with readability of $0.0001 \mathrm{~g}$.

\subsection{Androgen Assays}

Total serum testosterone was measured by radioimmunoassay (RIA) technique. The RIA-kit used, bought from PT. Karindo Alkestron, Jakarta, Indonesia, is manufactured by DPC (Diagnostic Products Corporation) USA. All the RIA process was undertaken at the Department of Physiology, Faculty of Medicine, Universitas Indonesia, Jakarta, Indonesia. 


\subsection{Sperm and Testiscular Histology Assessment}

After the epididymis was weighed, semen was squeezed and diluted with physiological saline. The suspension was used for sperm parameter analysis namely sperm counts, viability, motility and morphology. Spermatozoa was counted using a Neubauer haemocytometer under a light microscope at $400 \mathrm{x}$ magnification and expressed as million $/ \mathrm{ml}$ of suspension. Epididymal sperm motility quantified by counting both motile and immotile spermatozoa per unit area and expressed as an index. Furthermore, sperm viability examined using supravital staining made by adding $10 \mu \mathrm{L}$ of eosin Y-solution $0.5 \%$ into the $10 \mu \mathrm{L}$ of semen suspension. To quantify sperm morphology, the epididymis filtrate smeared on a clean glass slides by addition of a drop of $1 \%$ eosin. Once the object dried, observation done under a light microscope at 400x magnification and the abnormalities of either head or tail were noted.

The seminiferous tubular diameters, spermatogonia, primary spermatocytes and spermatid cell counts, was determined by fixingthe left testis from each rat in Bouin's solution. The organs were cut at the thickness $5 \mu \mathrm{m}$ and stained with hematoxylin and eosin and examined under a light microscope (Olympus-BX53) and Olympus Stream Image Analysis Software Version 1.7. The diameter of seminiferous tubules was determined by measuring the width of the tubules using oculometer. Spermatogonia, primary spermatocyte and spermatid cell counts were expressed as average values of spermatogenic cells in 10 seminiferous tubules.

\subsection{Statistical Analysis}

The data are presented as Mean \pm SD and analyzed statistically using a one-way ANOVA. Least Significance Difference (LSD) test was used as the post hoc test. All of the statistics that were applied are programmed in SPSS version 21.

\section{Results and Discussion}

Possible effects of pulp extract of white pitaya fruits are presented in Table 1. Among six parameters assessed, only the total serum testosterone shows a statistical significant difference between groups $(p<0.05)$. Based on the LSD test results, it can be stated that CPA treatment effectively reduces serum testosterone while pitaya fruit extract effectively increase the androgen concentration in the test rats when compared to the control ones. Moreover, extract of pitaya fruits effectively enhances the serum androgen both in normal and CPA-induced infertility in male rats. Therefore, pulp extract of white pitaya fruits can be used as a potent testicular dysfunction restorer in the male.

Table 1. Effects of pulp extract of white pitaya fruit on body weight, testis and epididymis weight, and total serum testosterone of male rats.

\begin{tabular}{llllll}
\hline Parameters & K 1 & K 2 & K 3 & K 4 & ANOVA (p-value) \\
\hline Initial body weight $(\mathrm{g})$ & $167.50 \pm 11.72^{\mathrm{a}}$ & $169.17 \pm 7.34^{\mathrm{a}}$ & $170.00 \pm 7.07^{\mathrm{a}}$ & $169.17 \pm 7.36^{\mathrm{a}}$ & .968 \\
Final body weight $(\mathrm{g})$ & $170.83 \pm 8.61^{\mathrm{a}}$ & $174.17 \pm 6.65^{\mathrm{a}}$ & $170.00 \pm 7.07^{\mathrm{a}}$ & $170.00 \pm 10.00^{\mathrm{a}}$ & .788 \\
Testis weight $(\mathrm{g})$ & $1.542 \pm 0.35^{\mathrm{a}}$ & $1.538 \pm 0.35^{\mathrm{a}}$ & $1.314 \pm 0.43^{\mathrm{a}}$ & $1.410 \pm 0.37^{\mathrm{a}}$ & .719 \\
Epididymis weight $(\mathrm{g})$ & $0.494 \pm 0.06^{\mathrm{a}}$ & $0.563 \pm 0.08^{\mathrm{a}}$ & $0.510 \pm 0.09^{\mathrm{a}}$ & $0.489 \pm 0.04^{\mathrm{a}}$ & .301 \\
Seminiferous diameter $(\mu \mathrm{m})$ & $277.83 \pm 18.14^{\mathrm{a}}$ & $284.54 \pm 16.89^{\mathrm{a}}$ & $265.32 \pm 15.27^{\mathrm{a}}$ & $279.60 \pm 19.48^{\mathrm{a}}$ & .300 \\
Total testosterone $(\mathrm{ng} / \mathrm{ml})$ & $2.402 \pm 0.564^{\mathrm{a}}$ & $3.65 \pm 0.97^{\mathrm{b}}$ & $0.708 \pm 0.281^{\mathrm{c}}$ & $3.422 \pm 0.710^{\mathrm{b}}$ & .000 \\
\hline
\end{tabular}

Values are mean $\pm \mathrm{SD}$, valuesof each parameters followed by the same superscript are not differ statistically at $\alpha=0.05$ based on $\mathrm{LSD}$ test. $\mathrm{K}_{1}=$ rats given $1 \mathrm{ml}$ $\mathrm{CMC} 1 \%$ (control); $\mathrm{K}_{2}=$ rats fed $500 \mathrm{mg} / \mathrm{kg}$ pitaya erxtract; $\mathrm{K}_{3}=$ rats treated with $25 \mathrm{mg} / \mathrm{kg}$ cyporoterone acetat; $\mathrm{K}_{4}=$ rats administered with $25 \mathrm{mg} / \mathrm{kg}$ cyporoterone acetat plus $500 \mathrm{mg} / \mathrm{kg}$ pitaya erxtract.

Tabel 2 showed values of sperm and spermatogenic cells parameters of male rats received four different treatments namely $1 \mathrm{ml} \mathrm{CMC} 1 \%$ (control), $500 \mathrm{mg} / \mathrm{kg}$ pitaya erxtract, $25 \mathrm{mg} / \mathrm{kg}$ cyporoterone acetat, and $25 \mathrm{mg} / \mathrm{kg}$ cyporoterone acetat plus $500 \mathrm{mg} / \mathrm{kg}$ pitaya erxtract. All testicular parameters significantly reduced by CPA treatment, except for spermatogonia counts $(\mathrm{p}>0.05)$. The pitaya fruit extract apparently enhances spermatozoa counts, sperm viability, sperm motility, and spermatid counts. However, pitaya fruit fail to restore the decrease of primary spermatocyte due to CPA induction.

Table 2. Effects of pulp extract of white pitaya fruit on the sperm and spermatogenic cell parameters.

\begin{tabular}{llllll}
\hline Paramaters & K 1 & K 2 & K 3 & K 4 & ANOVA (p-value) \\
\hline Spermatozoa counts $\left(10^{6} / \mathrm{ml}\right)$ & $23.35 \pm 2.98^{\mathrm{a}}$ & $29.72 \pm 4.65^{\mathrm{b}}$ & $10.67 \pm 3.19^{\mathrm{c}}$ & $28.76 \pm 6.81^{\mathrm{b}}$ & .000 \\
Sperm viability (\%) & $72.13 \pm 4.28^{\mathrm{a}}$ & $84.53 \pm 10.26^{\mathrm{b}}$ & $52.01 \pm 10.17^{\mathrm{c}}$ & $77.84 \pm 6.83^{\mathrm{b}}$ & .000 \\
Sperm motility (\%) & $65.05 \pm 6.26^{\mathrm{a}}$ & $79.29 \pm 10.46^{\mathrm{b}}$ & $46.31 \pm 9.97^{\mathrm{c}}$ & $74.36 \pm 8.13^{\mathrm{b}}$ & .000 \\
Sperm morphology (\% abnormal) & $8.29 \pm 1.04^{\mathrm{a}}$ & $6.57 \pm 1.03^{\mathrm{a}}$ & $12.86 \pm 2.30^{\mathrm{b}}$ & $7.48 \pm 2.13^{\mathrm{a}}$ & .000 \\
Spermatogonia & $10.22 \pm 1.18^{\mathrm{a}}$ & $9.99 \pm 1.97^{\mathrm{a}}$ & $8.66 \pm 1.59^{\mathrm{a}}$ & $8.80 \pm 1.51^{\mathrm{a}}$ & .239 \\
Primary spermatocyte counts & $62.84 \pm 12.37^{\mathrm{a}}$ & $66.28 \pm 7.79^{\mathrm{a}}$ & $42.92 \pm 6.27^{\mathrm{b}}$ & $60.71 \pm 9.91^{\mathrm{a}}$ & .002 \\
Spermatid counts & $114.33 \pm 10.01^{\mathrm{a}}$ & $127.24 \pm 12.45^{\mathrm{b}}$ & $90.75 \pm 7.02^{\mathrm{c}}$ & $125.43 \pm 10.73^{\mathrm{b}}$ & .000 \\
\hline
\end{tabular}

Values are mean $\pm \mathrm{SD}$, valuesof each parameters followed by the same superscript are not differ statistically at $\alpha=0.05$ based on LSD test. $\mathrm{K}_{1}=$ rats given $1 \mathrm{ml}$ $\mathrm{CMC} 1 \%$ (control); $\mathrm{K}_{2}=$ rats fed $500 \mathrm{mg} / \mathrm{kg}$ pitaya erxtract; $\mathrm{K}_{3}=$ rats treated with $25 \mathrm{mg} / \mathrm{kg}$ cyporoterone acetat; $\mathrm{K}_{4}=$ rats administered with $25 \mathrm{mg} / \mathrm{kg}$ cyporoterone acetat plus $500 \mathrm{mg} / \mathrm{kg}$ pitaya erxtract. 
The key finding of the study is that the white dragon fruit extracts play a role in steroidogenesis and spermiogenesis. Steroidogenic effect of the white pitaya fruits is most likely brought about by the phytosterol compounds. As has been reported by [9] it was revealed that pitaya fruits contain some phytosterol derivatives such as $\gamma$-sitosterol, stigmasterol, campesterol. The sterols have been recognized as good raw materials for the production of steroid hormones [15]. Other plants are known to contain a steroid derivative is black pepper or (Piper nigrum) [16], ginseng (Panax ginseng) [17], beach almond tree (Terminalia catappa) [18], tongkat ali or pasak bumi (Eurycoma longifolia Jack) [19], and ginger (Zingiber officinale var. rubrum) [20].

Black pepper fruit extract on male mice are proven to increase sex drive [21], enhance testosterone production and fertility potential [22]. The increase of steroidogenic activities in male rats given pitaya fruit extract may be also related to the role of bioactive compounds such as octadecadienoic acid; eicosane; squalene; octadecane; hexadecyl oxirane; ergosta-4, 6, 8 (14), 22-tetraen-3-one. Such bioative have been detected in preputial gland, as a pheromone carrier, and plays an important role in the sexual functioning and activities in rats [23]. Next, ginseng. This plant is well known as a medicinal plant that is proven to improve spermatogenesis [24], it turns out this plant contains a lot of phytosterols such as $\gamma$-sitosterol, stigmasterol, campesterol [17]. Beach almond tree, for another example, is also proven as an effective enhancer of sexual function in male rats [25]. Regarding tongkat ali (Eurycoma longifolia Jack.), [26] found that the plant extract acts as a potential agent for reversing the effects of estrogen by increasing spermatogenesis and sperm counts in rats. Lastly, the ginger which is also containing a lot of sterol suggested function as steroidogenic as well as spermatogenic [27].

The spermiogenetic effect of pitaya fruit extract, in addition can be accounted for by the content of phytosterols, may also be explained by the presence of antioxidant compounds, mainly polyphenol and ascorbic acid, in the plants belong to the Cactaceae family. As reported by [28], Hylocereus fruit shows high antioxidant activity. Antioxidant has many roles in the reproductive system. Such role was revealed by [29] based on a research tested the effect of ginger extract, which is rich in antioxidants, in rats, showed an increase in fertility. The relationship between the presence of antioxidants with the spermatogenesis and steroidogenesis has been also successfully demonstrated by [30] by testing the effects of pomegranate juice on testicular function of mice.

\section{Conclusion}

In conclusion, considering the white dragon fruit extract effectively increase the synthesis of testosterone as well as the spermiogenic parameters thus the pitaya fruit herbs can be used as an enhancer of sexual activity and fertility in male.

\section{References}

[1] Hess RA and de Franca R. L., 2008. Spermatogenesis and cycle of the seminiferous epithelium. Adv Exp Med Biol; 636: $1-15$.

[2] Weinbauer G. F., Luetjens C. M., Simoni M. and Nieschlag E., 2010. Physiology of Testicular Function. In Andrology, Male reproductive Health and Dysfunction. Nieschlag E., Behre $\mathrm{H}$. M., Nieschlag S. (Eds). XVII, Pp: 11-59.

[3] Agarwal A., Desai N. R., Ruffoli R. and Carpi A., 2008. Lifestyle and testicular dysfunction: A brief update, Biomed Pharmacother; doi: 10.1016/j.biopha.2008.07.052.

[4] McLachlan R (Rev). 2015. Androgen (testosterone) deficiency. Andrology Australia Fact Sheet: 1-2. Link.

[5] Malviya N., Jain S., Gupta V. B. and Vyas S., 2011. Recent Studies On Aphrodisiac Herbs For The Management Of Male Sexual Dysfunction--A Review. A Review. Acta Poloniae Pharmaceutica ñ Drug Research, Vol. 68 No. 1 pp. 3-8. Link.

[6] Mehta N., Sikka S. and Rajasekaran M., 2008. Rat as an Animal Model for Male Erectile Function Evaluation in Sexual Medicine Research. Laboratory Forum. J Sex Med; 5: 1278-1283. Link.

[7] Borreli L., 2015. Benefits Of Dragon Fruit: 6 Health Reasons To Eat More Of The Exotic Fruit. Jul 3, 12:00 Link.

[8] Tenore G. C., Novellino E. and Basile A., 2012. Nutraceutical potential and antioxidant benefits of red pitaya (Hylocereus polyrhizus) extracts. Journal of Functional Foods 4 (1).

[9] Luo H., Cai Y., Peng Z., Liu T. and Yang S., 2014. Chemical composition and in vitro evaluation of the cytotoxic and antioxidant activities of supercritical carbon dioxide extracts of pitaya (dragon fruit) peel. Chemistry Central Journal; 8: 1 .

[10] Vaithiyanathan V. and Mirunalini S., 2015. Quantitative variation of bioactive phyto compounds in ethyl acetate and methanol extracts of Pergularia daemia (Forsk.) Chiov. The Journal of Biomedical Research; 29 (2): 169-172. Link.

[11] Watcho P., Zelefack F., Ngouela S., Nguelefack T. B., Kamtchouing P., Tsamo E. and Kamanyi A., 2012. Enhancement of erectile function of sexually naïve rats by $\beta$ sitosterol and $\alpha-\beta$-amyrin acetate isolated from the hexane extract of Mondia whitei. Asian Pacific Journal of Tropical Biomedicine: S1266-S1269.

[12] Aziz F. A. and Noor M. M., 2010. Ethanol extract of dragon fruit and its effects on sperm quality and histology of the testes in mice. Biomedical Research; 21 (2): 126-130.

[13] Choo W. S. and Yong W. K., 2011. Antioxidant properties of two species of Hylocereus fruits. Advances in Applied Science Research; 2 (3): 418-425.

[14] Hoesla C. E., Saadb F., Po"ppela M., Altweina J. E., 2005. Reversible, Non-Barrier Male Contraception: Status and Prospects. European Urology 48 (2005) 712-723. Link.

[15] Wang F. Q., Yao K and Wei D. Z., 2011. From Soybean Phytosterols to Steroid Hormones, Soybean and Health, Prof. Hany El-Shemy (Ed.), ISBN: 978-953-307-535-8. Link. 
[16] Parmar, V. S., Jain, S. C., Bisht, K. S., Jain, R., Taneja, P., Jha, A., Tyagi, O. D., Prasad, A. K., Wengel, J., Olsen, C. E. and Boll, P. M., 1997. Phytochemistry of the Genus Piper. Phytochemistry; 46, 597-673.

[17] Lee M. H., Jeong J. H., Seo J. W., Shin C. G., Kim Y. C., In J. C., Yang D. C., Yi J. S. and Choi Y. E., 2004. Enhanced Triterpene and Phytosterol Biosynthesis in Panax ginseng Overexpressing Squalene Synthase Gene. Plant Cell Physiol. 45 (8): 976-984 Link.

[18] Praveena K., 2014. Phytochemical, Anti-microbial and Invitro antioxidant activity of Terminalia catappa. Int. J. of Pharm. Life Sci. 5 (2): 3325-3329. Link.

[19] Rahmalia A., Esyanti R. R. and Iriawati. A Qualitative and Quantitative Evaluation of Terpenoid and Alkaloid in Root and Stem of Pasak Bumi (Eurycomalongifolia Jack). Jurnal Matematika dan Sains, April 2011, Vol. 16 (1): 49-52. Link.

[20] Mercy O. A., Simeon O. O., Saheed A., Ayokunle O. and Temitope A. E., 2014. Analysis of Phenolic Compounds, Phytosterols, Lignans and Stilbenoids in Garlic and Ginger Oil by Gas Chromatography. J. Food Chem. Nutr. 02 (02) 2014. 53-60. Link.

[21] Sutyarso, Kanedi M. and Rosa E., 2015. Effects of Black Pepper (Piper nigrum Linn.) Extract on Sexual Drive in Male Mice. Research Journal of Medicinal Plant 9 (1): 42-47. Link.

[22] Sutyarso, Muhartono, and Kanedi M., 2016a. "The Effect of Fruit Extracts of Black Pepper on the Fertility Potential of Male Albino Rats." American Journal of Medical and Biological Research, 4 (1): 1-4.

[23] Ponmanickam P., Palanivelu K., Govindaraj S., Baburajendran R., Habara Y. and Archunan G., 2010. Identification of testosterone-dependent volatile compounds and proteins in the preputial gland of rat Rattus norvegicus. General and Comparative Endocrinology 167: 35-43. Link.

[24] Leung K. W. and Wong A. S. T., 2013. Ginseng and male reproductive function, Spermatogenesis, 3: 3, e 26391, DOI: 10.4161/spmg.26391. Link.

[25] Ratnasooriya W. D. and Dharmasiri M. G. 2000. Effects of Terminalia catappa seeds on sexual behaviour and fertility of male rats. Asian J Androl; 2 (3): 213-9. Link.

[26] Wahab N. A., Mokhtar N. M., Halim W. N. H. A. and Das S., 2010. The effect of Eurycoma longifolia Jack on spermatogenesis in estrogen-treated rats. CLINICS; 65 (1): 93-8. Link.

[27] Sutyarso, Muhartono, Susianti, Busman H. and Kanedi M., 2016b. Testicular Function of Rats Treated with Water Extract of Red Ginger (Zingiber officinale var. rubrum) Combined with Zinc. Journal of Food and Nutrition Research, 4 (3): 157-162. Link.

[28] Choo W. S. and Yong W. K., 2011. Antioxidant properties of two species of Hylocereus fruits. Advances in Applied Science Research; 2 (3): 418-425.

[29] Morakinyo A. O, Adeniyi O. S and Arikawe A. P., 2008. Effects of Zingiber Officinale on Reproductive Functions in the Male Rat. African Journal of Biomedical Research, 11: 329-334. Link.

[30] Türk G, Sönmez M, Aydin M, Yüce A, Gür S, Yüksel M, Aksu EH, Aksoy H., 2007. Effects of pomegranate juice consumption on sperm quality, spermatogenic cell density, antioxidant activity and testosterone level in male rats. Clin Nutr. 27 (2): 289-96. 